\title{
Continuous-flow hydrogenation over resin supported palladium catalyst for the synthesis of industrially relevant chemicals
}

\author{
Emil Kowalewski ${ }^{1}$ (D) Bartosz Zawadzki ${ }^{1}$ (D) Krzysztof Matus ${ }^{2}$ D \\ Kostiantyn Nikiforow ${ }^{1}$ (D) Anna Śrębowata ${ }^{1}$ (D)
}

Received: 14 November 2020 / Accepted: 27 December 2020 / Published online: 16 February 2021

(c) The Author(s) 2021

\begin{abstract}
Herein, the catalytic performance of palladium nanoparticles grafted on the polymeric $\mathrm{TSNH}_{2}$ (Tentagel-S-NH ) resin was investigated for continuous-flow liquidphase hydrogenation of two industrially relevant chemicals: 2-methyl-3-butyn-2-ol and nitrocyclohexane. We investigated the effect of process parameters such as temperature and pressure on $\mathrm{PdTSNH}_{2}$ activity and selectivity. Depending on the reaction conditions, well-dispersed PdNPs with average size of about $2 \mathrm{~nm}$ have shown very high flexibility in terms selectivity toward the desired products: 2-methyl-3buten-2-ol or 2-methyl-2-butanol in the case of 2-methyl-3-butyn-2-ol hydrogenation and cyclohexanone oxime or cyclohexylamine as the main product in the case of nitrocyclohexane conversion. The optimal reaction conditions for 2-methyl-3buten-2-ol formation were estimated at $25{ }^{\circ} \mathrm{C}$ and 5 bar, and in the case of cyclohexanone oxime formation at $40{ }^{\circ} \mathrm{C}$ and 10 bar. We demonstrated the general trend in the catalytic performance of $2.2 \mathrm{wt} \% \mathrm{Pd}$ grafted on Tentagel-S- $\mathrm{NH}_{2}$. Independently of the hydrogenated substrate, the increase in conversion leads to decreased selectivity to 2-methyl-3-buten-2-ol and cyclohexanone oxime at the expense of increasing the selectivity to 2-methyl-2-butanol or cyclohexylamine.
\end{abstract}

Anna Śrębowata

asrebowata@ichf.edu.pl

1 Institute of Physical Chemistry, Polish Academy of Sciences, Kasprzaka 44/52, 01-224 Warsaw, Poland

2 Materials Research Laboratory, Silesian University of Technology, Konarskiego 18A, 44-100 Gliwice, Poland 


\section{Graphic abstract}

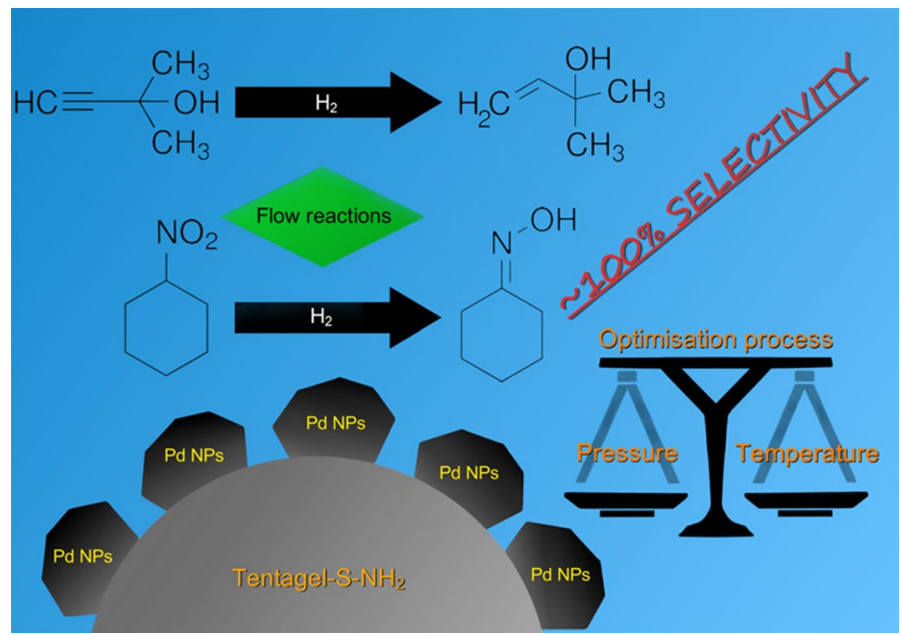

Keywords Flow hydrogenation $\cdot$ Resin supported palladium $\cdot$ Nitrocyclohexane 2-methyl-3-butyn-2-ol

\section{Introduction}

Hydrogenation, and especially catalytic hydrogenation, is one of the most important transformations in the chemical industry. Catalytic hydrogenations are carried out with homogeneous and heterogeneous catalysts using molecular hydrogen or its donors like isopropanol or formic acid [1-3].

Sustainable development requires modern, more intense, more efficient, and environmentally friendly technologies, and implementation of continuous-flow methods also belongs to this trend [4-10]. Therefore, in our studies, we implemented the liquid-phase continuous-flow hydrogenation of two of the crucial chemicals that have been studied minimally or have not been investigated at all in flow conditions: 2-methyl-3-butyn-2-ol (MBY) and nitrocyclohexane (NC).

The partial catalytic hydrogenation of 2-methyl-3-butyn-2-ol is an in-depth studied process, mainly because the $\mathrm{C} \equiv \mathrm{C}$ bond partial hydrogenation product (2-methyl3-buten-2-ol) is an essential intermediate for the industrial synthesis of vitamins (A, E), as well as a variety of perfumes [11]. The current manufacturing process is based on the Lindlar or other Pd-based heterogeneous catalysts under batch conditions. Although the desired product yields are in the range of 95-97\%, very fast catalyst deactivation is observed [12]. Continuous-flow hydrogenation of 2-methyl3-butyn-2-ol has been carried out only with $\mathrm{Pd} / \mathrm{TiO}_{2}, \mathrm{Pd}-\mathrm{TS}$ (3D printed Catalytic Static Mixers), bimetallic $\mathrm{PdZn} / \mathrm{TiO}_{2}$, and Lindlar catalyst [13-15]. The best results in terms of "alkene" yield were reported for a capillary microreactor with a 
bimetallic $\mathrm{Pd}_{25} \mathrm{Zn}_{75}$ catalyst supported on mesoporous $\mathrm{TiO}_{2}(89 \%)$ and for $5 \mathrm{wt} \%$ Pd-TS (100\%). The second desired product of 2-methyl-3-butyn-2-ol hydrogenation is 2-methyl-2-butanol-widely used as solvent in synthetic flavouring, pharmaceuticals, corrosion inhibitors, and making plastics and other chemicals [16]. However, 2-methyl-2-butanol is obtained by hydration of 2-methyl-2-butene in the presence of an acidic catalyst [17]. Therefore, getting a semi-saturated product (2-methyl-3-butene-2-ol) seems to be a more desired process.

On the other hand, we selected nitrocyclohexane because it is an excellent source of many useful chemicals. Additionally, until now, liquid-phase nitrocyclohexane hydrogenation has been conducted only in batch conditions, at elevated pressure and temperature $[18,19]$. According to our knowledge, there is only one article related to the hydrogenation of nitrocyclohexane, but under gas flow conditions [20]. Therefore, our experiments of the continuous-flow nitrocyclohexane hydrogenation in liquid phase open new perspectives in producing industrially relevant chemicals like e.g., cyclohexanone oxime (an essential component in polyamide manufacturing) or cyclohexylamine with its substantial role as a building block for pharmaceuticals.

Careful analysis of literature data displays the dominant role of noble metals, especially $\mathrm{Pd}$, as catalysts in heterogeneous hydrogenation. Nonetheless, very high hydrogenolytic ability makes palladium less selective towards specific products such as semi-hydrogenation of $\mathrm{C} \equiv \mathrm{C}$ to $\mathrm{C}=\mathrm{C}$, like in the case of hydrogenation of 2-methyl-3-butyn-2-ol or partial hydrogenation of nitrocyclohexane towards cyclohexanone oxime.

Therefore, to improve product-specificity, palladium catalysts are modified in different ways. One of the popular methods is based on the differences in metal nanoparticles' interaction with varying types of support (MSI) [21]. The interaction between the metal species and the support (MSI) could significantly affect the electronic structure and geometric configuration of metal species. The strength and type of MSI depend both on the size of the metallic species and the properties of the support [21]. For example, in the case of metal supported on oxides, the direct bond of a metal with cation (metal sites) or anion (oxygen sites) can be taken as the bridge to realize the metal-support interaction. Therefore, except the intrinsic electronic and geometric structures of metal species, surface properties of oxides as the supports determine the interaction between metal and oxides, which correspondingly influences the catalytic behaviours of metal species. On the other hand, it is challenging to induce strong MSI in the case of the carbon-supported materials, especially by depositing metal species on perfect carbon support [22]. Only the engineering defects or introduction of additional anchoring sites, and dangling bonds of edge carbon sites enable to build MSI and efficiently tune the catalytic behaviours of metal species. In consequence, the MSI plays a critical role in tuning the catalytic activity, selectivity and stability (e.g. resistance from sintering at a high temperature) of metal species on different supports [21,23].

Therefore, our study aimed to investigate the catalytic performance of Pd grafted on a polymeric resin (TS- $\mathrm{NH}_{2}$ ) in hydrogenation of two different substrates important in chemical technology. To the best of our knowledge, such studies have not yet been reported. Our results have shown that the combination of $2.2 \mathrm{wt} \% \mathrm{Pd}$ with polymeric resin shows high efficiency for the synthesis of industrially relevant 
chemicals (2-methyl-3-buten-2-ol, 2-methyl-2-butanol in the case of 2-methyl-3-butyn-2-ol conversion and cyclohexanone oxime or cyclohexylamine in the case of nitrocyclohexane conversion).

\section{Experimental}

\section{Catalyst synthesis and physicochemical characterization}

Tentagel-S- $\mathrm{NH}_{2}$ (Rapp Polymere $\left.\mathrm{GmbH}\right)$ in beads form with a diameter of $130 \mu \mathrm{m}$ and capacity of $0.2-0.35 \mathrm{mmol} / \mathrm{g}$ was used as the support for Pd nanoparticles. 2.2 wt $\%$ PdTS- $\mathrm{NH}_{2}$ was synthesized under ambient conditions at room temperature, using a two-step method. Initially, palladium (II) acetylacetone was mixed with sodium borohydride as a reducing agent. Palladium nanoparticles formed, which was indicated by a colour change from orange-yellow to black. In the second step, Pd nanoparticles were immobilized onto polymeric resin with amino groups by adding a portion of Tentagel-S- $\mathrm{NH}_{2}$ to nanoparticle solution and vigorous stirring $(1000 \mathrm{rpm})$ for $24 \mathrm{~h}$ at room temperature. During this step, polymeric resin was able to capture all palladium nanoparticles from the solution. After filtration, Pd catalyst was dried overnight at $120{ }^{\circ} \mathrm{C}$.

Elemental analysis was performed using atomic absorption spectrometry (AAS) and inductively coupled plasma-optical emission spectrometry (ICP-OES).

$\mathrm{X}$-ray photoelectron spectroscopy (XPS) spectra were recorded with a PHI 5000 VersaProbe ${ }^{\mathrm{TM}}(\mathrm{ULVAC}-\mathrm{PHI})$ scanning ESCA Microprobe using monochromatic Al-Koradiation $(\mathrm{h} \nu=1486.6 \mathrm{eV})$ from an X-ray source operating at $100 \mu \mathrm{m}$ spot size, $25 \mathrm{~W}$ power and $15 \mathrm{kV}$ acceleration voltage. High resolution (HR) XPS spectra were collected with a hemispherical analyser at the pass energy of $23.5 \mathrm{eV}$. The energy step size was $0.1 \mathrm{eV}$ and the photoelectron take-off angle was $45^{\circ}$ with respect to the surface. CasaXPS software was used to evaluate the XPS data. Deconvolution of XPS spectra was performed using a Shirley background and a Gaussian peak shape. The binding energies (BE) for all detected spectra were calibrated with respect to the $\mathrm{BE}$ of carbon $\mathrm{sp}^{3} \mathrm{C} 1 \mathrm{~s}$ at $285 \mathrm{eV}$ [24].

STEM and TEM experiments were performed on the electron microscope Titan G2 60-300 kV (FEI, Japan) equipped with EDAX EDS (energy-dispersive X-ray spectroscopy) detector. Microscopic studies of the catalysts were performed at an accelerating voltage of the electron beam equal to $300 \mathrm{kV}$. The sample was prepared by dispersion in pure alcohol using an ultrasonic cleaner; a drop of this suspension was placed on carbon films on copper grids.

\section{Catalytic tests}

The liquid-phase catalytic hydrogenation was performed using ThalesNano H-Cube Pro continuous-flow micro-reactor with an HPLC pump. Substrate (2-methyl-3-butyn-2-ol or nitrocyclohexane) solution in ethanol was flown through CatCart ${ }^{\circledR} 70$ cartridge with $0.1 \mathrm{~g}$ of a palladium catalyst. The hydrogen was generated in situ via 
water electrolysis. Both reactions were carried out with longer and shorter residence time (defined as bed volume/reactant flow rate) ranged within limits $0.4-2.70 \mathrm{~min}$, to optimise the most favourable reaction conditions. Finally, catalytic hydrogenation of 2-methyl-3-butyn-2-ol was conducted with $\mathrm{PdTSNH}_{2}$ over a wide range of temperatures $\left(10-100{ }^{\circ} \mathrm{C}\right)$ and pressures (1-20 bar) with reactant flow rate $1.5 \mathrm{ml} /$ min and $\mathrm{H}_{2}$ flow rate $60 \mathrm{ml} / \mathrm{min}$. Catalytic hydrogenation of nitrocyclohexane was also conducted with $\mathrm{PdTSNH}_{2}$ over a wide range of temperatures $\left(25-100{ }^{\circ} \mathrm{C}\right)$, but in the pressure range from 1 to 10 bar and flow rate of $0.3 \mathrm{ml} / \mathrm{min}$ and $\mathrm{H}_{2}$ flow rate $60 \mathrm{ml} / \mathrm{min}$. It is worth mentioning that during the reactions with $\mathrm{TSNH}_{2}$, there were no products of 2-methyl-3-butyn-2-ol or nitrocyclohexane hydrogenation. That excludes catalytic activity of the polymeric resin. Substrate conversion and product formation were analysed by gas chromatography (GC) Bruker 456 GC equipped with FID detector and BP $160 \times 0.25 \times 0.25$ column.

\section{Results and discussion}

Elemental analysis estimated by atomic absorption spectrometry (AAS) and inductively coupled plasma-optical emission spectrometry (ICP-OES) showed that Pd loading in $\mathrm{PdTSNH}_{2}$ is $2.2 \mathrm{wt} \%$.

The X-ray photoelectron spectroscopy measurement was carried out to determine the oxidation state of palladium nanoparticles. XPS results of the $\mathrm{Pd} 3 \mathrm{~d}$ region for PdTSNH2 are presented in Table 1. The dominant signals of $\mathrm{Pd} 3 \mathrm{~d}_{5 / 2}$ located at $334.38 \mathrm{eV}$ and $335.56 \mathrm{eV}$ relate to $\mathrm{Pd}$ in metallic form $[25,26]$. The shift with respect to the reported bulk position [27] and small asymmetry of the peak (results not shown) can be an evidence of a metallic species' presence in the nanoparticulated form [19]. The metallic palladium is also accompanied by oxide states ( $\mathrm{PdO}$ and $\mathrm{PdO}_{2}$ ). The total atomic concentration of $\mathrm{Pd}$ on the surface was estimated at $1.54 \%$.

Moreover, SEM and TEM investigations confirmed that palladium NPs are well dispersed on the surface with a narrow particle size range. An average metal particle size was estimated as $\sim 2 \mathrm{~nm}$ (Fig. 1).

$\mathrm{PdTSNH}_{2}$ catalytic performance was investigated in the continuous-flow hydrogenation of 2-methyl-3-butyn-2-ol (MBY) and nitrocyclohexane (NC) (Figs. 2 and 3 ). Hydrogenation of 2-methyl-3-butyn-2-ol over a wide range of temperatures and

Table 1 Binding energies of the $\operatorname{Pd} 3 d 5 / 2$ and $\mathrm{Pd} 3 d$ 3/2 peaks of the as-prepared PdTSNH 2 catalyst

\begin{tabular}{lllc}
\hline & BE $(\mathrm{eV})$ & FWHM & Area $(\%)$ \\
\hline 3d 5/2 & 334.38 & 1.36 & 48.11 \\
$3 \mathrm{~d} 3 / 2$ & 339.64 & 1.36 & 32.04 \\
$3 \mathrm{~d} \mathrm{5/2}$ & 335.65 & 1.36 & 8.29 \\
$3 \mathrm{~d} \mathrm{3/2}$ & 340.91 & 1.36 & 5.52 \\
$3 \mathrm{~d} \mathrm{5/2}$ & 336.95 & 1.36 & 3.63 \\
$3 \mathrm{~d} \mathrm{3/2}$ & 342.21 & 1.36 & 2.41 \\
\hline
\end{tabular}




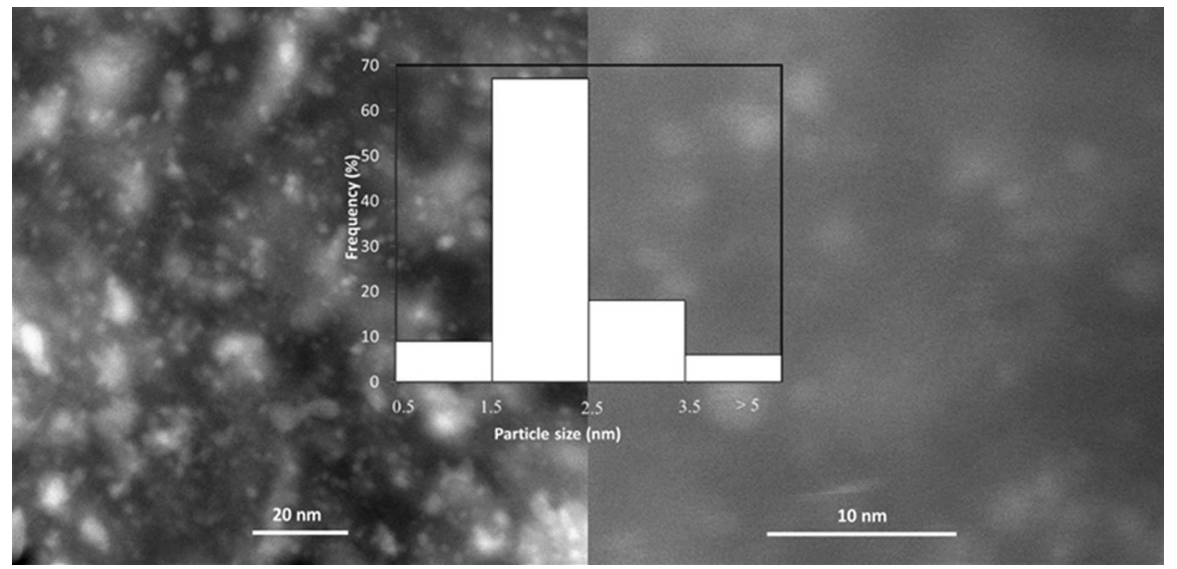

Fig. 1 STEM, TEM results, and palladium particle size distribution for as-prepared palladium nanoparticles grafted on the polymeric $\mathrm{TSNH}_{2}$ (Tentagel-S-NH ) resin (Pd loading $2.2 \mathrm{wt} \%$ )

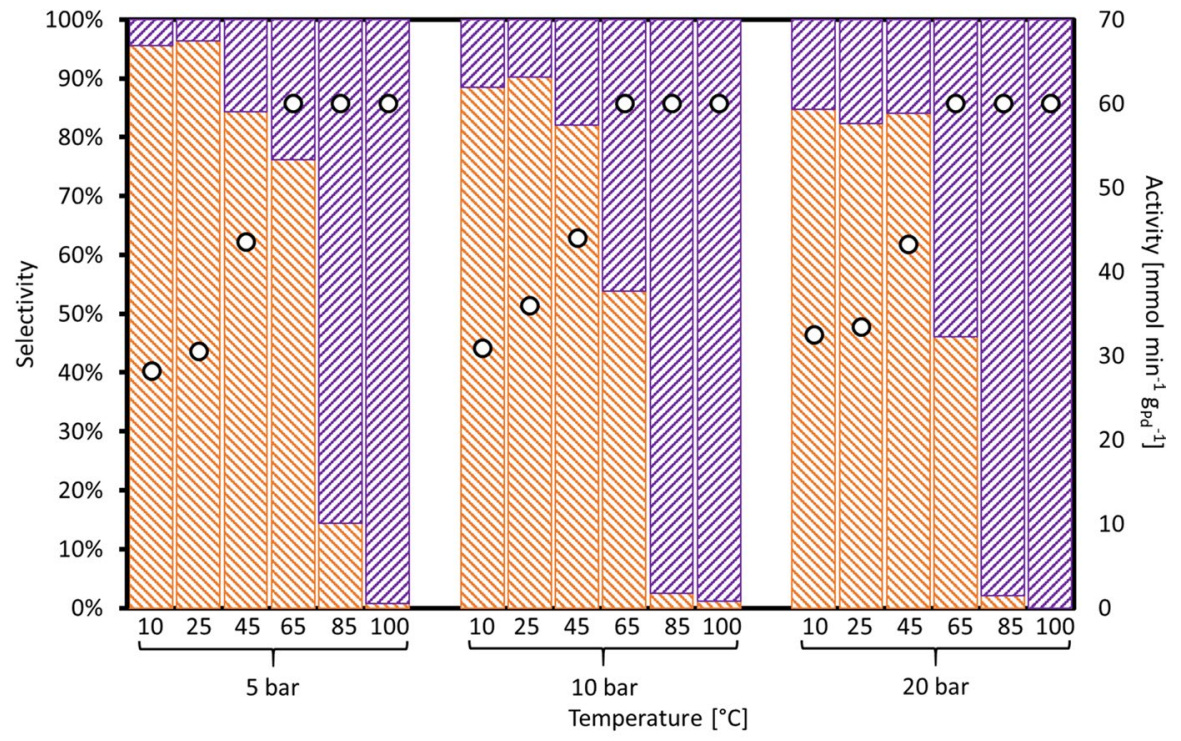

ه 2-methyl-3-buten-2-ol 2-methyl-2-butanol

Fig. 2 Effect of reaction conditions on the activity and selectivity of $2.2 \mathrm{wt} \% \mathrm{PdTSNH}_{2}$ in 2-metyl-3-butyn-2-ol hydrogenation towards 2-methyl-3-buten-2-ol and 2-methyl-2-butanol with $1.5 \mathrm{ml} / \mathrm{min}$ flow rate of the reactant

pressures showed that both temperature and pressure seem to affect 2-methyl-3buten-2-ol selectivity. Significantly, higher pressures led to significant changes in product selectivity (Fig. 2). Independent on the temperature, 2-methyl-2-butanol was formed as a major product of MBY hydrogenation at 1 bar and 3 bar, while higher pressures promote formation of the more desired product (unsaturated alcohol). 




Fig. 3 Effect of reaction conditions on the activity and selectivity of $2.2 \mathrm{wt} \% \mathrm{PdTSNH}_{2}$ in nitrocyclohexane hydrogenation towards cyclohexylamine and cyclohexanone oxime with $0.3 \mathrm{ml} / \mathrm{min}$ flow rate of the reactant

Moreover, the optimum temperature was found in the lower range. According to these tests, palladium grafted on Tentagel-S- $\mathrm{NH}_{2}$ showed $100 \%$ of selectivity toward the saturated alcohol over a rather wide range of temperatures and pressures. On the other hand, obtaining high selectivity to the partially hydrogenated product was possible only at specific reaction conditions. In respect to selectivity toward 2-methyl3-butene-2-ol, the optimum values were specified to be $25{ }^{\circ} \mathrm{C}$ and 5 bar, yielding $\mathrm{PdTSNH}_{2}$ activity of ca. $67 \mu \mathrm{mol} / \mathrm{min}$ with $93 \%$ of the selectivity to the unsaturated alcohol. Additionally, the palladium catalyst maintained the reported performance for the entire time on stream (ca. $300 \mathrm{~min}$ ).

The direct comparison of our results with literature data is not trivial due to different reaction conditions (e.g., residence time, substrate concentration, $\mathrm{H}_{2} /$ substrate ratio) and different palladium loading, in comparison to earlier studies [9, 15]. Although our results may seem slightly worse or comparable to the industrial standard catalysts such as Lindlar's and Pd-Nanoselect catalysts [15], the general trend with respect of the selectivity toward unsaturated product was the same as in the work of Kundra et al. [15]. Increasing both temperature and pressure was found to benefit 2-methyl-3-butyn-2-ol conversion at the selectivity's cost toward the unsaturated product. Additionally, our measurements showed that the pressure increase seems to minimally affect the substrate activity over the temperature range of $10-45^{\circ} \mathrm{C}$, but results in a decrease in selectivity to 2-methyl-3-buten-2-ol at the expense of an increase in selectivity to 2-methyl-2-butanol (Table 2). Moreover, independently of the hydrogen pressure, increase in the temperature up to $65^{\circ} \mathrm{C}$ did 
Table 2 2-methyl-3-butyn-2-ol hydrogenation results for liquid flow rate- $1.5 \mathrm{ml} / \mathrm{min}, \mathrm{H}_{2}$ flow rate- $60 \mathrm{ml} / \mathrm{min}$, residence time$0.5 \mathrm{~min}$

\begin{tabular}{|c|c|c|c|}
\hline Pressure (bar) & $\begin{array}{l}\text { Tempera- } \\
\text { ture }\left({ }^{\circ} \mathrm{C}\right)\end{array}$ & $\begin{array}{l}\text { 2-Methyl-3-buten- } \\
\text { 2-ol selectivity (\%) }\end{array}$ & $\begin{array}{l}\text { Activity } \\
\text { ( } \mu \mathrm{mol} / \\
\min )\end{array}$ \\
\hline \multirow[t]{6}{*}{5} & 10 & 91 & 62.19 \\
\hline & 25 & 93 & 67.33 \\
\hline & 45 & 73 & 95.79 \\
\hline & 65 & 61 & 132.11 \\
\hline & 85 & 7 & 132.11 \\
\hline & 100 & 0.3 & 132.11 \\
\hline \multirow[t]{6}{*}{10} & 10 & 79 & 68.13 \\
\hline & 25 & 82 & 79.19 \\
\hline & 45 & 70 & 96.93 \\
\hline & 65 & 37 & 132.11 \\
\hline & 85 & 1.2 & 132.11 \\
\hline & 100 & 0.6 & 132.11 \\
\hline \multirow[t]{6}{*}{20} & 10 & 73 & 71.48 \\
\hline & 25 & 72 & 73.63 \\
\hline & 45 & 69 & 95.22 \\
\hline & 65 & 29 & 132.11 \\
\hline & 85 & 1 & 132.11 \\
\hline & 100 & 0 & 132.11 \\
\hline
\end{tabular}

not affect the very high activity (100\% of 2-methyl-3-butyn-2-ol conversion) but strongly decreased the selectivity towards unsaturated product e.g. $61 \%$ of selectivity for 5 bar and $65{ }^{\circ} \mathrm{C}$ and only $7 \%$ at $85{ }^{\circ} \mathrm{C}$ at the same pressure (Table 2). As a result of our research, we have also determined the optimal pressure and temperature conditions ( 5 bar, $25^{\circ} \mathrm{C}$ ) for the production of 2-methyl-3-buten-2-ol, the key intermediate in the synthetic method of vitamin $\mathrm{A}$ and $\mathrm{E}$ production.

Continuous-flow hydrogenation of nitrocyclohexane (NC) on $\mathrm{PdTSNH}_{2}$ led to formation of cyclohexylamine and cyclohexanone oxime. Fig. 3 shows the influence of the reaction conditions on the selectivity towards the two desired products. The selectivity to cyclohexanone oxime did not depend as much on pressure as it depended on the reaction temperature (Fig. 3, Table 3). Generally, under higher pressures, higher temperature is needed to obtain $100 \%$ selectivity to cyclohexanone oxime. It is $25{ }^{\circ} \mathrm{C}$ at 5 bar and $40{ }^{\circ} \mathrm{C}$ at 10 bar. Every time, increase in temperature led to increased activity at a given pressure, accompanied by an increased selectivity towards the second desired product-cyclohexylamine. However, comparison of the catalyst activity at 1, 2, 5, and 10 bar indicates higher $\mathrm{PdTSNH}_{2}$ activity at lower temperature and pressure. Maximum activity and maximum selectivity to cyclohexylamine $(96 \%)$ are obtained for 2 bar and $100{ }^{\circ} \mathrm{C}$ (Table 3 ).

It should be mentioned here that this is the first reported continuous-flow nitrocyclohexane hydrogenation in liquid-phase, according to our knowledge. Only hydrogenations at batch conditions were successfully conducted with noble metals as catalysts $[18,19,28]$ with cyclohexylamine or oxime cyclohexanone formation. 
Table 3 Nitrocyclohexane hydrogenation results for liquid flow rate- $0.3 \mathrm{ml} / \mathrm{min}, \mathrm{H}_{2}$ flow rate- $60 \mathrm{ml} / \mathrm{min}$, residence time$2.7 \mathrm{~min}$

\begin{tabular}{|c|c|c|c|}
\hline Pressure (bar) & $\begin{array}{l}\text { Tempera- } \\
\text { ture }\left({ }^{\circ} \mathrm{C}\right)\end{array}$ & $\begin{array}{l}\text { Cyclohexanone oxime } \\
\text { selectivity (\%) }\end{array}$ & $\begin{array}{l}\text { Activity } \\
(\mu \mathrm{mol} / \\
\mathrm{min})\end{array}$ \\
\hline \multirow[t]{6}{*}{1} & 25 & 100 & 0.07 \\
\hline & 40 & 52 & 1.11 \\
\hline & 55 & 23 & 2.03 \\
\hline & 70 & 15 & 2.02 \\
\hline & 85 & 8 & 6.20 \\
\hline & 100 & 5 & 6.35 \\
\hline \multirow[t]{6}{*}{2} & 25 & 96 & 0.07 \\
\hline & 40 & 72 & 0.81 \\
\hline & 55 & 47 & 0.94 \\
\hline & 70 & 20 & 1.78 \\
\hline & 85 & 18 & 2.66 \\
\hline & 100 & 4 & 11.87 \\
\hline \multirow[t]{6}{*}{5} & 25 & 100 & 0.07 \\
\hline & 40 & 88 & 0.10 \\
\hline & 55 & 53 & 0.12 \\
\hline & 70 & 24 & 0.66 \\
\hline & 85 & 12 & 0.77 \\
\hline & 100 & 8 & 1.96 \\
\hline \multirow[t]{6}{*}{10} & 25 & 91 & 0.07 \\
\hline & 40 & 100 & 0.10 \\
\hline & 55 & 68 & 0.81 \\
\hline & 70 & 34 & 0.84 \\
\hline & 85 & 19 & 1.25 \\
\hline & 100 & 16 & 2.45 \\
\hline
\end{tabular}

Therefore, we are sure that our results are promising from this point of view and open a new perspective in the efficient nitrocyclohexane conversion.

\section{Conclusions}

Our results clearly show that $\mathrm{PdTSNH}_{2}$ is an effective catalyst in hydrogenation processes to synthetise industrially relevant chemicals (2-methyl-3-buten-2-ol and cyclohexanone oxime). High activity and $\sim 100 \%$ of the selectivity towards desired products of 2-methyl-3-butyn-2-ol or nitrocyclohexane hydrogenation strongly depend on the reaction conditions and the presence of very small $(\sim 2 \mathrm{~nm})$ palladium nanoparticles grafted on the Tentagel-S-NH $\mathrm{NH}_{2}$ resin. The optimal reaction conditions for 2-methyl-3-buten-2-ol formation were estimated at $25{ }^{\circ} \mathrm{C}$ and 5 bar and in the case of cyclohexanone oxime formation at $40{ }^{\circ} \mathrm{C}$ and 10 bar. We also demonstrated the general trend in the catalytic performance of 
$2.2 \mathrm{wt} \% \mathrm{Pd}$ grafted on Tentagel-S-NH $\mathrm{N}_{2}$. Independently of the hydrogenated substrate, the increase in conversion leads to decreased selectivity to 2-methyl-3buten-2-ol and cyclohexanone oxime, at the expense of increasing the selectivity to 2-methyl-2-butanol or cyclohexylamine.

Acknowledgements This work was partially sponsored by National Science Centre in Poland within projects UMO-2019/33/B/ST5/01271 and UMO 2018/31/N/ST5/02555.

Author contributions EK: investigation, conceptualization, funding acquisition, methodology. BZ, KM, $\mathrm{KN}$ : investigation. AŚ: conceptualization, data curation, formal analysis funding acquisition, methodology, project administration, supervision validation, writing—original draft.

Funding National Science Centre in Poland within projects UMO-2019/33/B/ST5/01271 and UMO 2018/31/N/ST5/02555.

Data availability The authors declare that all data supporting the findings of this study are available within the article.

\section{Compliance with ethical standards}

Conflict of interest The authors have no conflicts of interest and have no competing interests to declare that are relevant to the content of this article.

Open Access This article is licensed under a Creative Commons Attribution 4.0 International License, which permits use, sharing, adaptation, distribution and reproduction in any medium or format, as long as you give appropriate credit to the original author(s) and the source, provide a link to the Creative Commons licence, and indicate if changes were made. The images or other third party material in this article are included in the article's Creative Commons licence, unless indicated otherwise in a credit line to the material. If material is not included in the article's Creative Commons licence and your intended use is not permitted by statutory regulation or exceeds the permitted use, you will need to obtain permission directly from the copyright holder. To view a copy of this licence, visit http://creativecommons.org/licen ses/by/4.0/.

\section{References}

1. Zanotti-Gerosa A, Angelini T, Roseblade S (2020) Efficient and selective solvent-free homogeneous hydrogenation of aldehydes under mild reaction conditions using [RuCl2(dppb)(ampy)]. Tetrahedron Lett 61:151677. https://doi.org/10.1016/j.tetlet.2020.151677

2. Wang D, Deraedt C, Ruiz J, Astruc D (2015) Sodium hydroxide-catalyzed transfer hydrogenation of carbonyl compounds and nitroarenes using ethanol or isopropanol as both solvent and hydrogen donor. J Mol Catal A 400:14-21. https://doi.org/10.1016/j.molcata.2015.01.024

3. Wang T, Du J, Sun Y et al (2020) Catalytic transfer hydrogenation of biomass-derived furfural to furfuryl alcohol with formic acid as hydrogen donor over CuCs-MCM catalyst. Chin Chem Lett. https://doi.org/10.1016/j.cclet.2020.07.044

4. Giziński D, Błachucki W, Śrębowata A et al (2018) On-the-fly catalyst accretion and screening in chemoselective flow hydrogenation. ChemCatChem 10:3641-3646. https://doi.org/10.1002/ cctc. 201800581

5. Ley SV, Stewart-Liddon AJP, Pears D et al (2006) Hydrogenation of aromatic ketones, aldehydes, and epoxides with hydrogen and Pd(0)EnCat ${ }^{\mathrm{TM}}$ 30NP. Beilstein J Org Chem 2:2-6. https ://doi.org/10.1186/1860-5397-2-15

6. Sedelmeier J, Ley SV, Lange H, Baxendale IR (2009) Pd-EnCat ${ }^{\mathrm{TM}}$ TPP30 as a catalyst for the generation of highly functionalized aryl- and alkenyl-substituted acetylenes via 
microwave-assisted sonogashira type reactions. Eur J Org Chem. https://doi.org/10.1002/ ejoc. 200900344

7. Desai B, Kappe CO (2005) Heterogeneous hydrogenation reactions using a continuous flow high pressure device. J Comb Chem 7:641-643. https://doi.org/10.1021/cc050076x

8. Roper KA, Lange H, Polyzos A et al (2011) The application of a monolithic triphenylphosphine reagent for conducting Appel reactions in flow microreactors. Beilstein J Org Chem 7:16481655. https://doi.org/10.3762/bjoc.7.194

9. Elias Y, Rudolf von Rohr P, Bonrath W et al (2015) A porous structured reactor for hydrogenation reactions. Chem Eng Process Process Intensif 95:175-185. https://doi.org/10.1016/j. cep.2015.05.012

10. Avril A, Hornung $\mathrm{CH}$, Urban A et al (2017) Continuous flow hydrogenations using novel catalytic static mixers inside a tubular reactor. React Chem Eng 2:180-188. https://doi.org/10.1039/c6re0 0188 b

11. Bagiay AK, Gurariy LL, Kuleshov GG (1988) Physical properties of compounds used in vitamin synthesis. J Chem Eng Data 33:512-518. https://doi.org/10.1021/je00054a035

12. Crespo-Quesada M, Grasemann M, Semagina N et al (2009) Kinetics of the solvent-free hydrogenation of 2-methyl-3-butyn-2-ol over a structured Pd-based catalyst. Catal Today 147:247-254. https:// doi.org/10.1016/j.cattod.2008.09.035

13. Okhlopkova LB, Kerzhentsev MA, Ismagilov ZR (2016) Capillary microreactor with a catalytic coating based on mesoporous titanium dioxide for the selective hydrogenation of 2-methyl-3-butyn2-ol. Kinet Catal 57:497-503. https://doi.org/10.1134/S0023158416040091

14. Liguori F, Coiai S, Passaglia E, Barbaro P (2013) Strong cation exchange with innocence: synthesis and characterization of borate containing resins and macroporous monoliths. Macromolecules 46:5423-5433. https://doi.org/10.1021/ma401120v

15. Kundra M, Bin Mohamad Sultan B, Ng D et al (2020) Continuous flow semi-hydrogenation of alkynes using 3D printed catalytic static mixers. Chem Eng Process - Process Intensif 154:108018. https://doi.org/10.1016/j.cep.2020.108018

16. Pohanish RP (2002) Sittig's handbook of toxic and hazardous chemicals and carcinogens. Elsevier Inc, Amsterdam

17. Papa AJ (2003) Amyl Alcohols. Kirk-Othmer encyclopedia of chemical technology. Wiley, Hoboken

18. Corma A, Serna P (2006) Chemoselective hydrogenation of nitro compounds with supported gold catalysts. Science 313:332-334. https://doi.org/10.1126/science.1128383

19. Liu P-L, Zhang H-K, Liu S-H et al (2013) Palladium supported catalysts for nitrocyclohexane hydrogenation to cyclohexanone oxime with high selectivity. ChemCatChem 5:2932-2938. https:// doi.org/10.1002/cctc.201300377

20. Wang X, Perret N, Keane MA (2013) Gas phase hydrogenation of nitrocyclohexane over supported gold catalysts. Appl Catal A 467:575-584. https://doi.org/10.1016/j.apcata.2013.07.061

21. Lou Y, Xu J, Zhang Y et al (2020) Metal-support interaction for heterogeneous catalysis: from nanoparticles to single atoms. Mater Today Nano 12:100093

22. Park SA, Kim DS, Kim TJ, Kim YT (2013) Strong interaction between Pt and thiolated carbon for electrocatalytic durability enhancement. ACS Catal 3:3067-3074. https://doi.org/10.1021/cs400 $649 n$

23. Diwell AF, Rajaram RR, Shaw HA, Truex TJ (1991) The role of ceria in three-way catalysts. Stud Surf Sci Catal 71:139-152. https://doi.org/10.1016/S0167-2991(08)62975-4

24. Beamson G, Briggs D (1993) High Resolution XPS of Organic Polymers: The Scienta ESCA300 Database. J. Chem. Educ. 70:A25. https://doi.org/10.1021/ed070pA25.5

25. Voogt EH, Mens AJM, Gijzeman OLJ, Geus JW (1996) XPS analysis of palladium oxide layers and particles. Surf Sci 350:21-31. https://doi.org/10.1016/0039-6028(96)01028-X

26. Bukhtiyarov AV, Prosvirin IP, Bukhtiyarov VI (2016) XPS/STM study of model bimetallic Pd-Au/ HOPG catalysts. Appl Surf Sci 367:214-221. https://doi.org/10.1016/j.apsusc.2016.01.173

27. Brun M, Berthet A, Bertolini JC (1999) XPS, AES and Auger parameter of Pd and PdO. J Electron Spectros Relat Phenom 104:55-60. https://doi.org/10.1016/s0368-2048(98)00312-0

28. Serna P, López-Haro M, Calvino JJ, Corma A (2009) Selective hydrogenation of nitrocyclohexane to cyclohexanone oxime with $\mathrm{H}_{2}$ on decorated Pt nanoparticles. J Catal 263:328-334. https://doi. org/10.1016/j.jcat.2009.02.025 
Publisher's Note Springer Nature remains neutral with regard to jurisdictional claims in published maps and institutional affiliations. 